\title{
Assessment of the Proportion and Associated Factors of Episiotomy at Public Health Institutions of Axum Town, Tigray Region, North Ethiopia, 2015
}

\author{
Yayehyirad Yemaneh ${ }^{1}$, Ermias Sahile ${ }^{1}$, Addisu Alehegn ${ }^{1}$, Abel Girma ${ }^{2}$, Carmen C Roubles $^{3}$, Seifu \\ Kebedde $^{3}$, Zerihun Minlikalew ${ }^{3}$, Abere Yekoye ${ }^{3}$, Kirubel Ante-Ab ${ }^{4}$, Eden Dagnachew ${ }^{5}$, Wondewossen \\ Nigussie ${ }^{6}$
}

${ }^{1}$ Department of Midwifery, College of Health Sciences, Mizan-Tepi University, Mizan-Teferi ,Ethiopia

${ }^{2}$ Department of Public Health, College of Health Sciences, Mizan-Tepi University, Mizan-Teferi, Ethiopia

${ }^{3}$ Department of Midwifery, College of Health Sciences Mekelle University, Mekelle, Ethiopia

${ }^{4}$ Department of Midwifery, College of Health Sciences Dre-Dawa University, DreDawa, Ethiopa

${ }^{5}$ Department of Midwifery, Mizan-Aman Health Sciences College, Mizan-Teferi, Ethiopia

${ }^{6}$ Department of Nursing, College of Health Sciences, Mizan-Tepi University, Mizan-Teferi, Ethiopia

Corresponding author: Yemaneh $\mathrm{Y}$, Lecturer, Department of Midwifery, College of Health Sciences, Mizan-Tepi University, Ethiopia, Tel: +251912087869; E-mail: buchiatuog@gmail.com

Received date: June 24, 2017; Accepted date: August 04, 2017; Published date: August 11, 2017

Copyright: @ 2017 Yemaneh Y, et al. This is an open-access article distributed under the terms of the Creative Commons Attribution License, which permits unrestricted use, distribution, and reproduction in any medium, provided the original author and source are credited.

Citation: Yemaneh Y, Sahile E, Alehegn A, Girma A, Robles C, et al. Assessment of the Proportion and Associated Factors of Episiotomy at Public Health Institutions of Axum Town, Tigray Region, North Ethiopia, 2015. Crit Care Obst Gyne. 2017, 3:11.

\section{Abstract}

Background: Episiotomy means simply a 2nd degree tear to enlarge outlet, for expulsion of the fetus with tolerable damage or injury. Historically, episiotomy has been an element of vaginal delivery, with the rationale of preventing extensive perennial tearing. Incidence varies according to parity, patient population, indication, and health care provider practicing obstetrics. Study findings showed that higher rate of episiotomy in Ethiopia.

Objective: To assess the proportion of episiotomy performance and its associated factors in Axum town public health institutions 2015.

Methods: Facility based cross- sectional study design was employed in three Public health institutions in Axum town, Tigray, Ethiopia 2015. Information was retrieved retrospectively from a total of 338 maternal charts that were selected using systematic random sampling technique. The data were collected using pre-tested and structured data extraction format. Using SPSS version 20 software, descriptive statistics, bivariate and multivariate logistic regression analysis was done and during bivariate logistic regression analysis those variables at $p$-value $<0.2$ was transferred to multivariate logistic regression analysis and during Multivariate logistic regression analysis Variables at P-value $<0.05$ were considered as statistically significant and AOR with $95 \% \mathrm{Cl}$ was used to control for possible confounders and to interpret the result. The result is summarized using tables, graphs and charts for different variables.
Results: Out of 338 deliveries the proportion of episiotomy was $140(41.44 \%)$.The odds of episiotomy practice were 1.8 times greater among primipara when compared with multiparous women $[\mathrm{AOR}=1.89(1.08,3.23)], 8.9$ times greater among mothers whose labor were assisted by vacuum as compared to those who delivered by normal vaginal delivery $[A O R=8.99(4.25,19.03)], 4.7$ times greater among deliveries whose fetal presentation was face when compared with vertex presentations $[A O R=4.76(1.94$, 11.67)].

Conclusion: The proportion of episiotomy practice is high. Parity, face presentation, mode of delivery, Birth Attendant and 1st minute Apgar score were significantly associated with practice of episiotomy.

Keywords: Proportion; Episiotomy; Associated factors; Axum

\section{Introduction}

Episiotomy means simply a 2nd degree tear to enlarge the outlet, for expulsion of the fetus with tolerable damage or injury. Historically, episiotomy has been an element of vaginal delivery, with the rationale of preventing extensive perennial tearing extending to include the involvement of the anal sphincter and damage to the pelvic floor. Episiotomy was originally recommended to help in labor and deliveries and its routine performance began to be defined by Pomeroy in 1918. During many years this routine practice was accepted and taught as an absolute truth in big obstetrics services, although not based on well conducted and controlled studies. Episiotomy is one of the most commonly performed surgical procedures worldwide, 
performed in $30-63 \%$ of all deliveries and, in some regions, in up to $93 \%$ of nulliparous women [1].

Like other procedures episiotomy has its own indications among these some are to shorten birth of a distressed baby, for instrumental breech delivery, to protect premature head from birth injury \& prevent third degree tears [2-5].Incidence varies according to parity, patient population, indication, and health care provider practicing obstetrics. In 2000, Robinson and associates found Practice of Episiotomy (21\%), (33\%) and (55\%) among Midwives, Medical school faculty and Private practice providers [5]. Evidences from previous studies have indicated that the routine use of episiotomy may do more harm than benefit [6]. The restrictive versus routine use of episiotomy is associated with a lower risk of posterior perennial trauma, need for suturing perennial trauma, and healing complications at seven days [7]. It also has beneficial effects on reducing longterm complications [8]. A prospective cross sectional study done in Canada Toronto revealed that episiotomy was associated with more pain, excessive bleeding, wound hematoma, infection and breakdown [2].

Nonetheless, episiotomy which is essentially a surgical procedure is generally associated with complications, some of which include pain, hemorrhage, and local anesthetic toxicity, wound infection and wound breakdown [9]. The occurrence of these complications may be influenced by the skill and experience of the attending physician. Episiotomy also interferes with the mother's comfort during the postpartum period. These morbidities may have a profound impact on a woman's recovery in the puerperium, and on subsequent health and psychological wellbeing.

\section{Methodology}

\section{Study design}

Institutional based cross-sectional study design was employed to collect information on the performance of episiotomy retrospectively in 3 public health institution of axum town north Ethiopia.

\section{Study area and period}

The study was conducted from October 12-31-2015 in 3 public health institutions of Axum town. It is the most wellknown of North Tigray for its rich temples and obelisks. It is located at a distance of around 1004 kilometers from Addis Ababa in north direction and around 248 kilometers from Mekelle the capital city of the Tigray region. Based on central statistics agency as of July the town has total population of 56576 of this there are a total of 30293 females and 26,283 males [10-13]. Among this 1530 women gave birth during the study period, from January to June 2015.In the town there are 79 skilled birth attendants and 1 public hospital, 2 health centers, 3 private clinics which provides a maternal and neonatal health services so the study was conducted in those three public health institutions namely St. Mary hospital, Axum health center and millennium health center (Figures 1-4).

\section{Target population}

All deliveries in Axum town public health institutions.

\section{Source population}

All delivery charts from January-June2015.

\section{Study population}

Sampled delivery charts selected based on inclusion criteria.

\section{Study unit}

Individual delivery charts.

\section{Inclusion and exclusion criteria}

Inclusion criteria: All vaginal deliveries.

Exclusion criteria: Incompletely documented charts.

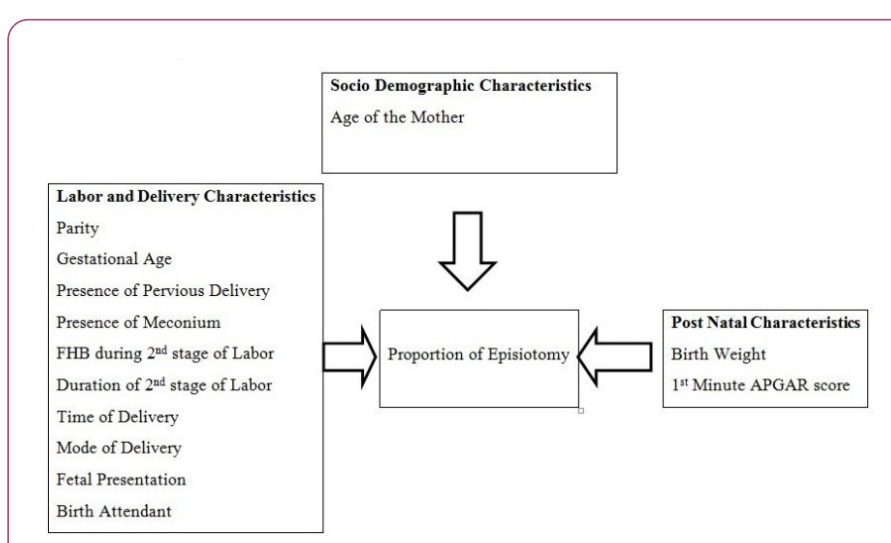

Figure 1: Showing factors affecting practice of Episiotomy.

Sample size, sampling technique and sampling procedure

Sample size: The sample size for proportion of episiotomy was determined by using single population proportion formula using a basic assumption of $95 \%$ confidence level, $5 \%$ margin of error andproportion ( $\mathrm{P}$ as 50\%) and using the formula,

$$
\mathrm{n}=\frac{(\mathrm{Z} \alpha / 2)^{2} \mathrm{P}(1-\mathrm{P})}{\mathrm{d}^{2}(0.05) 2}, \mathrm{ni}=(1.96)^{2} \quad 0.5(.5)=384
$$

Since the source of population is $<10,000$ by using correction formula

$\mathrm{nf}=\mathrm{ni} / 1+\mathrm{ni} / \mathrm{N}=306.9=307$ then adding $10 \%$ contingency $\sim 31$ finally we got 338

$\mathrm{nf}=338$ and pretest $=10 \%=33.8 \sim 34$ charts

Assumptions;

ni=initial sample size ; 384

$\mathrm{nf}=$ Final sample size

Z=confidence level which were $95 \%$ 


\section{$\mathrm{P}=$ proportion $50 \%$}

\section{$d=$ the margin of error were taken as $5 \%$}

$\mathrm{N}=$ total number of deliveries in the town for the study time $=1530$

Sampling technique: Systematic sampling technique was used to select the study subjects then calculating $\mathrm{K}$ for each gave us around 4 .

Sampling procedure: First by calculating the total number of deliveries conducted during the study period in the public health institutions (for the 6 months there was a total of 1530) found in the town then allocating proportionally to the public health institutions based on the number of deliveries.

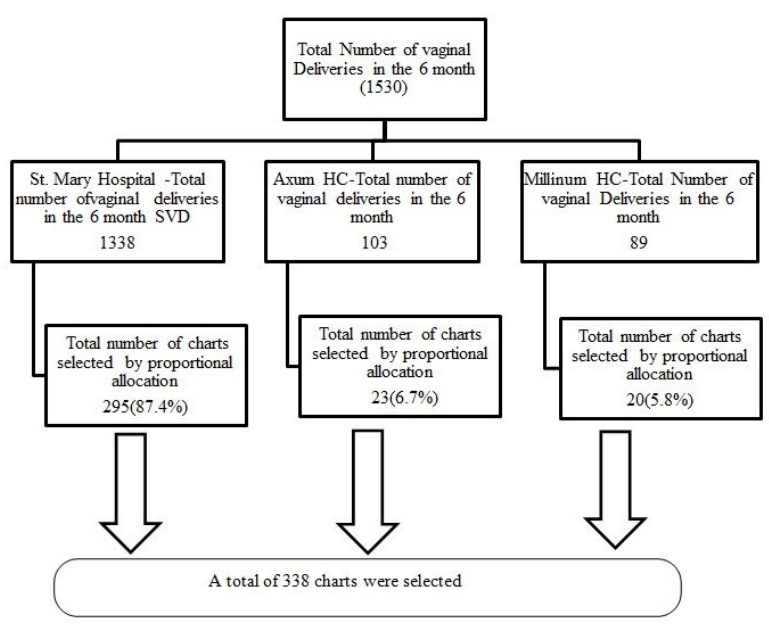

Figure 2: Schematic presentation of sampling Procedure.

Data collection procedure: By using proportional allocation and based on the systematic sampling procedure a total of 338 charts were selected from 1530 delivery charts from January to June 2015. The data were collected retrospectively by reviewing maternal charts using a checklist which was developed from different literatures addressing the socio demographics, obstetrics, labor and delivery and post natal characteristics. There were 5 data collectors all BSc. health professionals and have been paid per questioner. In addition $3 \mathrm{MSc}$. midwives gave the data collectors a one day discussion about the questionnaire and how to use it to collect the data.

Data quality control: Data quality was ensured during collection, coding, entry and analysis. To increase the quality of data during data collection three teams namely data collectors, supervisors and investigators was assigned and properly designed, structured and pretested data extraction format was used. Training was given to the data collectors and supervisors to prevent any confusion and have a common understanding about the tool. Each card was checked for its consistency, provision of full information and appropriate documentation. Supervision of data collectors were conducted by supervisors and include observation of how the data collectors were collecting data.
The data collectors were instructed to write card number on the data extraction format during the data collection so that any identified errors were traced back using the card number. The filled data extraction format was checked by data collectors, supervisors and Principal Investigators for completeness and clarity on a daily basis.

Data processing and analysis: The entire returned data extraction format were checked for completeness and clarity, cleaned manually, coded and entered in to SPSS version 20 statistical package to be cleaned, edited and analyzed by the principal investigator for further analysis. Frequencies and Percentage was used to summarize descriptive statistics, tables and charts were used for data presentation. Logistic regression model was used and bivariate logistic regression was done to determine association between each independent variable with dependent variable. Variables with $\mathrm{P}$ - value $<0.2$ in bivariate analysis were entered in to next multivariate analysis and multiple logistic regression analysis were done to determine relative prediction level of independent variables to the outcome variable. Variables having $p$-value $<0.05$ were considered as statistically significant and AOR with $95 \% \mathrm{Cl}$ was used to control for possible confounders and to interpret the result.

Ethical consideration: After approval of the document by Mekelle university collage of health sciences institutional review board then the ethical approval and official letter was obtained from, Mekelle university collage of health sciences institutional review board. Permissions was obtained from Axum town health bureau. A letter was then sent to the study health institutions and permission was obtained to proceed with the study. There was no personal identifier attached during data retrieval. There was no intention to collect any additional information from the institution and there were no risks that follow with participation in this research.

During the study the institution had full right to withhold information, skip questions or to withdraw from the study at any time. Nobody needed to explain the reason for withdrawal. It is also explained that there would be no effect at all in the benefit or other administrative effect that the institution would get from their refusal to participate.

Dissemination of results: The findings of the study was presented and submitted to Mekelle University Collage of Health Sciences Department of Midwifery to serve as reference materials for subsequent studies and teaching purposes.

The research finding was also be submitted to the Tigray regional health bureau and the specified health institutions. Efforts will also be done to publish in peer reviewed journals to make it accessible for all interested in the programmatic and research aspects of the proportion of episiotomy and associated factors. It will also be presented in scientific conferences. 


\section{Results}

\section{Socio-demographic characteristics}

Out of the 338 maternal charts reviewed the majority $209(61.8 \%)$ of the mothers who gave birth were in the age group19-26years, $98(29 \%)$ of were in the age group of 27-34 and $31(9.2 \%)$ were in the group of $35-42$ years. The mean age of the mothers was $25+5.1$ years with the maximum of 42 years and minimum of 19 years.

\section{Labor and delivery characteristics}

Out of 338maternal delivery charts reviewed 195(57.7\%) were primipara, out of this 78 had one pervious c/s delivery, and $304(89.9 \%)$ deliveries were term and $221(65.4 \%)$ of them have history of previously delivery (Table 1 ).

Table1: Distribution of Deliveries by their Obstetric characteristics Axum town North Ethiopia 2015 ( $n=338)$.

\begin{tabular}{|l|l|l|l|}
\hline \multicolumn{2}{|l|}{ Variables } & Frequency & Percent (\%) \\
\hline \multirow{2}{*}{ Parity } & Primi Para & 195 & 57.7 \\
\cline { 2 - 4 } & Multi Para & 143 & $42.30 \%$ \\
\hline \multirow{2}{*}{$\begin{array}{l}\text { Gestational age from } \\
\text { LNMP (in Weeks) }\end{array}$} & Preterm & 15 & $4.40 \%$ \\
\cline { 2 - 4 } & Term & 304 & $89.90 \%$ \\
\cline { 2 - 4 } & Post term & 19 & $5.60 \%$ \\
\hline \multirow{2}{*}{ Previous Delivery } & Yes & 221 & $65.40 \%$ \\
\cline { 2 - 4 } & No & 117 & $34.60 \%$ \\
\hline
\end{tabular}

Regarding Duration of $2^{\text {nd }}$ stage of Labor Majority $178(52.7 \%)$ of the labors $2^{\text {nd }}$ stage of Labor stayed $<30$ minutes, $134(39.6 \%)$ stayed 30 minut- 60 minutes and $26(7.71 \%)$ Stayed $>60$ Minutes and the mean duration of $2^{\text {nd }}$ stage of labor was $37+21.34$ minutes and are in the range of maximum of 100 minutes and minimum of 5 Minutes. Out of 338maternal charts reviewed in the public health institution $255(75.4 \%)$ of the fetal presentation were Vertex, 51(15.1\%) were breech, and 32(9.5\%) were Face. From a total of 338 charts reviewed 242(71.6\%) were with normal condition of $\mathrm{FHB}$, and $96(28.4 \%)$ were with abnormal fetal heart beat status (57(16.9\%) Brady cardiac and 39(11.5\%) were with tachycardia).

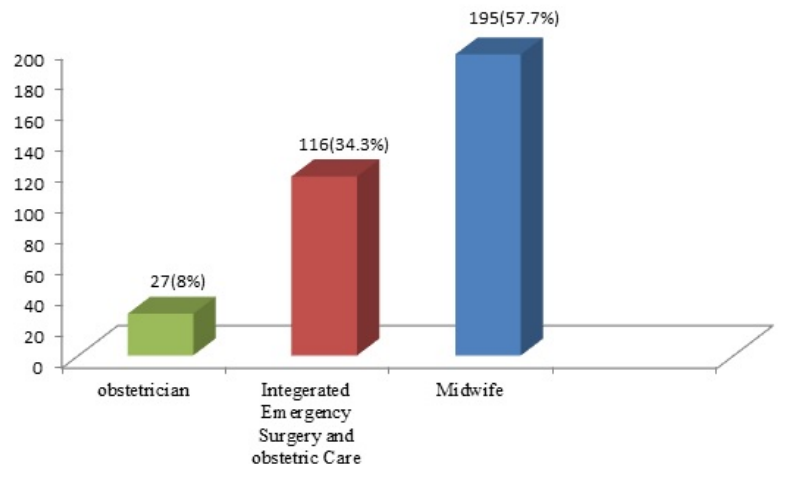

Figure 3: Distributions of deliveries by their attending health.

Out of three hundred thirty eight delivery charts, $82(24.3 \%)$ had meconium in the amniotic fluid evidenced during labor and delivery at the time of vaginal examination. The proportion episiotomy was $41.4 \%$.Two hundred two (59.8\%) births were conducted during the night time, and $183(54.1 \%)$ of the deliveries were normal vaginal delivery, $61(18 \%)$ of them were assisted by vaccum and $94(27.8 \%)$ were assisted by forceps.

\section{Post natal characteristics}

Out of three hundred thirty eight delivery charts reviewed the birth weight of three hundred one $(89.1 \%)$ of the neonates were within normal birth weight ranging from $2.50 \mathrm{~kg}$ to $3.99 \mathrm{~kg}$ and two hundred forty five $(72.5 \%)$ had $1^{\text {st }}$ minute Apgar score of $>7$ minutes.

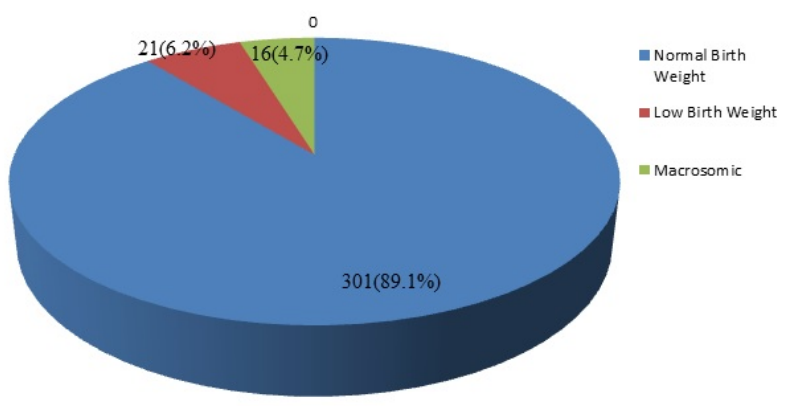

Figure 4: Distribution of deliveries by their birth weight.

\section{Factors associated with episiotomy}

It was observed that presence of meconium, neonatal weight, parity, fetal presentation, mode of delivery; birth attendant and $1^{\text {st }}$ minute Apgar score were significantly associated with performance of episiotomy practice during bivariate analysis and transferred to multivariate analysis and presence of meconium, neonatal weight have found to be statistically insignificant during multivariate analysis but parity, face presentation, mode of delivery, birth attendant and 1st minute Apgar score were statistically significantly associated with practice of episiotomy after multivariate analysis (Table 2). 
The odds of episiotomy practice were 1.8 times greater among pimipara when compared with multiparous women [AOR=1.86(1.08, 3.23)].

From 338 charts episiotomy practice was 4.7 times greater among deliveries whose fetal presentation was Face when compared with vertex presentations $[A O R=4.76(1.94,11.67)]$.

Episiotomy practice were 8.9 times greater among those whose labor were assisted by vacuum as compared to those who delivered by $\operatorname{NVD}[A O R=8.99(4.25,19.03)]$. Similarly, the odds of episiotomy practice was almost 3.4 times greater among whose labor were assisted by forceps as compared to those who delivered by NVD [AOR=3.49(1.84, 6.59)].

The odds of episiotomy practice was almost 3.4 times greater among integrated emergency surgery and obstetric care students than midwives [AOR=3.44(1.22, 9.72)].

The practice of episiotomy was almost 5.1 times greater among those deliveries with low Apgar score than compared to those with normal Apgar score $[A O R=5.11(2.80,9.33)]$.

Table 2: Logistic regression analysis of factors associated with episiotomy.

\begin{tabular}{|c|c|c|c|c|c|}
\hline \multicolumn{2}{|l|}{ Variable } & \multicolumn{2}{|c|}{ Episiotomy } & \multirow{2}{*}{$\begin{array}{l}\operatorname{COR}(95 \% \mathrm{CI}) \\
2.06(1.32,3.25)\end{array}$} & \multirow{2}{*}{$\begin{array}{l}\text { AOR }(95 \% \mathrm{CI}) \\
1.86(1.08,3.23)^{*}\end{array}$} \\
\hline & Primi & $\begin{array}{l}\text { Yes } \\
95\end{array}$ & $\begin{array}{l}\text { NO } \\
100\end{array}$ & & \\
\hline Parity & Multi(R) & 45 & 98 & & \\
\hline & Low Birth(R) & 7 & 14 & & \\
\hline & Normal Birth & 122 & 179 & $1.36(0.54,3.48)$ & $0.82(.29,2.29)$ \\
\hline Weight & Macrosomic & 11 & 5 & $4.4(1.09,17.72)$ & $1.72(0.36,8.24)$ \\
\hline \multirow{3}{*}{ Fetal Presentation } & Vertex(R) & 100 & 155 & & \\
\hline & Breech & 20 & 31 & $1(0.54,1.85)$ & $0.77(0.35,1.67)$ \\
\hline & Face & 20 & 12 & $2.58(1.21,5.52)$ & $4.76(1.94,11.67)^{* *}$ \\
\hline \multirow{2}{*}{ Presence of Meconium } & Yes & 46 & 36 & $2.20(1.33,3.65)$ & $1.80(0.97,3.32)$ \\
\hline & $\mathrm{NO}(\mathrm{R})$ & 94 & 162 & & \\
\hline \multirow{3}{*}{ Mode of Delivery } & $N \vee D(R)$ & 48 & 135 & & \\
\hline & Vaccum & 42 & 19 & $6.22(3.3,11.72)$ & $8.99(4.25,19.03)^{\star *}$ \\
\hline & Forceps & 50 & 44 & $3.2(1.9,5.39)$ & $3.49(1.84,6.59)^{\star *}$ \\
\hline \multirow{2}{*}{ Birth attendant } & Midwife & 67 & 128 & $1.24(0.52,2.99)$ & $1.54(0.56,4.19)$ \\
\hline & IESOC & 65 & 51 & $3.03(1.23,7.47)$ & $3.44(1.22,9.7)^{*}$ \\
\hline \multirow{3}{*}{1 Minute apgar score } & Obstetrician(R) & 8 & 19 & & \\
\hline & $<6$ Minutes & 65 & 28 & $5.26(3.13,8.45)$ & $5.11(2.80,9.33)^{\star *}$ \\
\hline & >7Minutes(R) & 75 & 170 & & \\
\hline
\end{tabular}

\section{Discussion}

The present study attempted to assess proportion of episiotomy practice and associated factors at public health institutions of Axum town.

The study indicated that proportion of episiotomy practice in the institution was found to be $41.44 \%$ which was almost 1.2 times higher than the recommendation of World Health Organization [14]. The result of this study was very close to the previous studies done at Black Lion hospital, and Brigham Hospital Boston Massachusetts which has found that the prevalence of episiotomy was $40.2 \%$ and $40.6 \%$ respectively $[5,10]$.
This study has found a higher prevalence of episiotomy compared to a study done at Jimma teaching Hospital, Mizan Aman General Hospital, Zaria, Nigeria and Pernambuco Brazil where the prevalence of episiotomy was $25 \%$ and $30.6 \%, 35.6 \%$ and $29.1 \%$ respectively [15-17]. This higher result may be due to fact that this study has assessed the prevalence of episiotomy in three institution, high prevalence of instrumental delivery in the study area, because most of the mothers who gave birth was primi so they may perform episiotomy for most of the primi mothers by referring to the previous guidelines, the institution is serving as teaching institution for 3 universities intigray region including both the undergraduate and post graduate students of health sciences, inappropriate documentation meaning the health professional may document the tear as episiotomy after repairing it, and the health professionals perception about 
routine use of episiotomy and may be due to the country policies towards the selective use of episiotomy. Since 2002 selective episiotomy became normal at the Professor Monteiro de Moraes maternity center in Recife, state of Pernambuco, Brazil, and indicated in pregnant patients with acute fetal distress and inadequate progress of labor [16].

But it is slightly lower than the finding in Lagos (54.9\%), Abia (45\%) and Enugu (62.1\%). All in Nigeria and in Benin (46.6\%) $[9,11,24,28]$, respectively. The differences can be explained by the time difference, which may suggest a moderate reduction probably due to the increased emphasis on the restrictive use of episiotomy at the institution in line with evidence based recommendations and an increment of quality of service and upgrading the service providers through pre-service and inservice training.

However it is still far higher than recommended by the World Health Organization which is $10 \%-30 \%$ [14].

Most of the Factors associated with episiotomy among laboring mothers are similar to other studies done in Addis Ababa, Jimma, Mizan- Aman and Ogbomosho Nigeria, $[10,15,18]$.

The odds of episiotomy practice were 1.8 times greater among primipara when compared with multiparous women $[A O R=1.89(1.08,3.23)]$.this result is consistent with the study done in Ogbomosho, Zaria all in Nigeria which states that a high association of primi parity with performance of episiotomy $[17,18]$. The justifications for this high episiotomy index are not clear yet but the old recommendation of routine episiotomy in primiparous patients performed by many health Professionals, might still have an influence in the indication of this procedures for these patients [19-25].

From 338charts the episiotomy practice were 4.7 times greater among deliveries whose fetal presentation was face when compared with vertex presentations [AOR=4.76(1.94, 11.67)]. This result is consistent with a prospective cohort $s$ study done in Zaria Nigeria [17]. A significant association of episiotomies with the fetal mal-presentation is not unexpected as it is the routine in this center to perform episiotomies during instrumental and difficult deliveries, as it is the practice in other centers [26-29].

Episiotomy practice was 8.9 times greater among whose labor were assisted by vacuum as compared to those who delivered by normal vaginal delivery $[A O R=8.99(4.25,19.03)]$. Similarly, the odds of episiotomy practice was 3.4 times greater among whose labor was assisted by forceps as compared to those who delivered by NVD [AOR=3.49(1.84, 6.59)]. This result is consistent with the study done in Black Lion Teaching Hospital, Zaria Nigeria, Ogbomoso Nigeria, Brazil, and Brigham Hospital Boston Massachusetts [5,10,16,17,18].

The odds of episiotomy practice was almost 3.4 times greater among integrated emergency surgery and obstetric care students than midwives $[A O R=3.44(1.22,9.7)]$. This is consistent with a study done in Oman which revealed that the odds of episiotomy practice were almost 2.26 times higher in bachelor holders than diploma holders [30]. This may be due to most of the complicated deliveries in this center are conducted by Senior health professionals.

Episiotomy practice was 5.1 times greater among those deliveries who had low Apgar score than those with normal Apgar score $[A O R=5.11(2.80,9.33)]$. This finding is consistent with the study done at Petrolane, Brazil which found practice of episiotomy on newborns with lower Apgar index were nearly twice as likely to occur in episiotomy [30].

\section{Strength and Limitations of the Study}

\section{Strength of the study}

This study was conducted in health institutions that are owned by Public that will make it more representative.

\section{Limitations of the study}

Other variables pertinent to the theme, indication $s$ for episiotomy performance presence of medical or obstetrical complications were not assessed due to poor documentation. The Cross sectional nature of the study is not able to assess some variables like factors related to later period of birth like post-operative outcome.

\section{Conclusions}

The proportion of episiotomy practice in Axum town Public health institutions is high. Practice of episiotomy found to have statistically significant association with: parity, face presentation, mode of delivery, birth attendant and 1st minute Apgar score.

The possible reasons that make the proportion of episiotomy high: high prevalence of instrumental delivery in the study area, because most of the mothers who gave birth was primi so they may perform episiotomy for most of the primi mothers by referring to the previous guidelines, the institution is serving as teaching institution for 3 universities in tigray region including both the undergraduate and post graduate students of health sciences,, and the health professionals perception about routine use of episiotomy.

\section{Acknowledgment}

We would like to forward our best gratitude to all our data collectors for their unreserved and dedicated cooperation to make this research a reality. We would also like to thank Mekelle University College of Health Sciences for letting us to have this opportunity to conduct research by covering the total budget required. Our best gratitude also goes to St. Marry Hospital, Mellinium Health center and Axum Health Center Administration in General and to Health professionals and Record office staffs who working in the study institution in specific. Last but not least we would like to thank administrative staffs of Axum town health Department for the provision of indispensable information and cooperation when needed. 


\section{Author Responsibilities}

All authors of this research paper have directly participated in the planning, execution, or analysis of this study. All author of this research have read and approved the final version submitted. The contents of this manuscript have not been copyrighted or published previously. The contents of this manuscript are not under consideration for publication elsewhere. The contents of this manuscript were not been copyrighted, submitted, or published elsewhere, while acceptance by the Journal is under consideration. There are no directly related manuscripts or abstracts, published or unpublished, by any authors of this paper.

\section{Conflict of Interest}

All the authors declare that "this research finding is the original article and there is no conflict of interest regarding the publication of this research finding".

\section{References}

1. Althabe F, Belizan JM, Berge I (2002) Episiotomy Rates In Primiparous Women In Latin America; Hospital Based Descriptive Study BJM 324: 945-946.

2. Macathur A, Macarthur C (2004) Incidence, Severity, And Determinants of Perennial Pain After Vaginal Delivery: A Prospective Cohort Study. Am j Obstet Gynecol 191: 199-204.

3. Eason E, Labrecque M, Marcoux S, Mondor M (2002) Anal Incontinence After Child Birth. CMAJ 166: 320-330.

4. Meyn L, Weber AM (2002) Episiotomy Use In United States 1979-1997. Obstet Gynecol 4: 49-53.

5. Robinson JN (2000) Predictors Of Episiotomy Use At Fist Spontaneous Vaginal Delivey. Obstatic \& Gynecology 96: 214-218.

6. Carroli G, Mignini (2009) Episiotomy For Vaginal Birth. Cochrane Data Base Syst Ev 20: 1

7. Mutihir JT, Ujah IOA (2005) Episiotomies In The Jos University Teaching Hospital. Highland Med Research J 3: 31-35.

8. Jovanovic NS, Kocijancic DM, Terzic MM (2011) Current Approach To Episiotomy: Inevitable O Unnecessary? Central European Journal Of Medicine 6: 685-690.

9. BelloO O, Anorlu Al (2002) Episiotomies In Nigeria : Should Their Use Be Restricted? Niger Postgrad Med J 99: 13-16.

10. Kiros K, Lakew Z (2006) Magnitude of Episiotomy In Teaching Hospital In Addis Ababa, Ethiopia. Ethiop Med J 44: 205-209.

11. Izuka E (2014) Prevalence And Predictors Of Episiotomy Among Women At Fist Birth In Enugu South East Nigeria. Annals Of Medical And Health Science Research 4: 928.

12. Calypkan E, Ozturk N, Akyan B, Yalvac S, Dilbaz B, et al. (2003) Analysis Of 47145 Births In The Health Centers. Third Step: An Epidemiologic Study MN-Gorm 9: 88-91.
13. Graham ID, Graham DF (1997) Episiotomy Counts: Trends And Prevalence In Canada,1981/1982 To 1993/1994. Birth 24: 141-147.

14. Lijestrand J (2003) Episiotomy For Vaginal Birth : RHL Commendatory(Last Revised:20 October 2003).Geneva: World Health Organization Reproductive Health Library

15. Marai W (2002) A Two Years Retrospective Review Of Episiotomy At Jimma Teaching Hospital, South Western Ethiopia. Ethiop Med J 40: $141-148$

16. Cavalho C, Souza AS, MoraesFilho OB (2010) Prevalence And Factors Associated With Practice Of Episiotomy At Maternity School In Recife, Pernambuco, Brazil. Rev Assoc Med Bras

17. Scot K (2015) Episitomy. Lancet 56: 333-339.

18. Sule ST, Shittu SO (2003) Puerperal Complication Of Episiotomy At Ahmadu Bello University Teaching Hospital, Zaria, Nigeria. East African J Med 80: 351-356.

19. Alayande BT, Amole IO, Akin D (2012) Relative Frequency And Predictors Of Episiotomy In Ogbomoso, Nigeria. Internet Journal of Medical Update-EJOUNAL 7: 2

20. Inyang EE, Umoiyoho A (2013) The Practice Of Episiotomy In University Teaching Hospital In Nigeria: How Satisfactory? International Journal Of Medicine And Biomedical Research 1: 68-72.

21. Friese K (1994) Routine Of Vs Selective Episiotomy. The Lancet 343: 486-487.

22. Mitiku G ,Beyene W, Geremew M (2015) Assessment of Episiotomy Practice in Mizan-Aman General Hospital, Ethiopia. Journal of Health Medicine and Nursing 20: 12-20.

23. BaskettTF, Calader AA, Arulkumaran S (2014) Munro Kerr's Operative Obstetrics. 2014: Elsevier Health Sciences.

24. Trinh AT, Khambalia A, Ampt A, Morris JM, Roberts CL (2013) Episiotomy Rate In Vietnamese- Born Women In Australia: Support For A Change In Obstetric Practice In Vietnam. Bull World Health Ogan 91: 350-356.

25. Raisanen S, Vehvilainen JK, Heinonen S (2010) Need For And Consequences Of Episiotomy In Vaginal Birth : A Critical Approach. Midwifey 26: 348-356.

26. Scott Jr (2005) Episiotomy And Vaginal Trauma. ObstetGynecolClin North Am 32: 307-321.

27. Onah HE, Akani $\mathrm{Cl}$ (2004) Rates And Predictors Of Episiotomy In Nigerian Women. Trop J Obstet Gynecol 21: 44-45.

28. Otoido VO, Ogbonmwan SM, Okonofua FE (2000) Episiotomy In Nigeria. Int J Gynecol Obstet 68: 13-17.

29. Ogunyemi D, Manigat B, Marquis J, Bazargan M (2006) Demographic variations and clinical associations of episiotomy and severe perineal lacerations in vaginal delivery. J Nat Med Assoc 98: 1874-1881.

30. Al-Ghammari K (2016) Predictors of routine episiotomy in primigravida. Applied Nursing Research 29: 131-135.

31. Ana Carolina (2014) occurrence and factors associated to the practice of episioto myjnursufpe on line. recife 8: 257-263. 